Brit. J. industr. Med., 1951, 8, 298.

\title{
AN ENVIRONMENTAL STUDY OF THE CHROMATE INDUSTRY
}

\author{
BY \\ MONAMY BUCKELL and D. G. HARVEY \\ From the Department for Research in Industrial Medicine, Medical Research Council, Hampstead, \\ and The London Hospital
}

The purpose of this paper is to give the results of an environmental study of the three chromate producing factories in Great Britain investigated by Bidstrup (p. 302), and to compare the results with those of Bourne and Yee (1950) in a similar study of the industry in the United States of America. The study reported in this communication was completed over a year ago, and before the work of Bourne and Yee was published. Thus it has not been possible to apply the experimental methods of these authors and so improve the comparison of the two studies.

\section{Manufacture and Properties of some Common Compounds of Chromium}

Chromium compounds are of considerable importance to industry, and according to Thorpe and Whiteley (1946a) Great Britain produces more than 10,000 tons of potassium dichromate per annum. The main step in the manufacture of the various chromium compounds involves the conversion of the water insoluble ore, chromite, into a water soluble chromate. The process generally adopted is essentially similar to that described by Partington (1946).

Finely ground chromite $\left(\mathrm{FeOCr}_{2} \mathrm{O}_{3}\right)$ is intimately mixed with sodium carbonate and crude calcium carbonate (as dolomite or limestone). The mixture is conveyed to a rotating furnace where it is roasted. A series of chemical reactions occur which are probably represented by the following equations :

(1) $4\left(\mathrm{FeOCr}_{2} \mathrm{O}_{3}\right)+4 \mathrm{Na}_{2} \mathrm{CO}_{3}=4 \mathrm{Na}_{2} \mathrm{Cr}_{2} \mathrm{O}_{4}+4 \mathrm{FeO}+4 \mathrm{CO}_{2}$

(2) $4 \mathrm{Na}_{2} \mathrm{Cr}_{2} \mathrm{O}_{4}+4 \mathrm{Na}_{2} \mathrm{CO}_{2}+60_{2}=8 \mathrm{Na}_{2} \mathrm{CrO}_{4}+4 \mathrm{CO}_{2}$ $4 \mathrm{FeO}+\mathrm{O}_{2}=2 \mathrm{Fe}_{2} \mathrm{O}_{3}$

The calcium carbonate is added to increase the heat of the reaction. Although some calcium chromate is formed during the process, this is mostly decomposed by excess soda. The red hot product of roasting, frit, is transferred to wash tanks where hot water is carefully added. This "flooding" gives rise to a strongly exothermic reaction. As a result, the soluble sodium monochromate is leached out, and the liquor run off and is treated according to special requirements.

In order to obtain the dichromate, the monochromate liquor is treated with dilute sulphuric acid in special tanks. The reaction proceeds as in equation (4).

(4) $2 \mathrm{Na}_{2} \mathrm{CrO}_{4}+\mathrm{H}_{2} \mathrm{SO}_{4}=\mathrm{Na}_{2} \mathrm{SO}_{4}+\mathrm{Na}_{2} \mathrm{Cr}_{2} \mathrm{O}_{7}+\mathrm{H}_{2} \mathrm{O}$

The sodium sulphate is less soluble than the dichromate and much of it separates out. This is removed and the mother liquor concentrated. More sodium sulphate separates and is removed. The final mother liquor contains the dichromate which crystallises out on concentration. In order to obtain potassium dichromate a concentrated solution of a potassium salt (e.g. potassium chloride) is added to a concentrated solution of sodium dichromate. Potassium dichromate is precipitated immediately. Another important chromium compound, chromic acid $\left(\mathrm{CrO}_{3}\right)$, is prepared by adding strong sulphuric acid to a concentrated solution of potassium dichromate. Deep scarlet crystals of the acid are formed. The reaction proceeds as shown in equation (5).

(5) $\mathrm{K}_{2} \mathrm{Cr}_{2} \mathrm{O}_{7}+\mathrm{H}_{2} \mathrm{SO}_{4}=\mathrm{K}_{2} \mathrm{SO}_{4}+\mathrm{H}_{2} \mathrm{O}+2 \mathrm{CrO}_{3}$

Partial drying of the principal products, namely, potassium and sodium mono- and dichromates, is carried out in filter presses and the process completed in centrifugal dryers or heated baths.

The chief compounds which are manufactured are the chromates and dichromates of sodium and potassium and also chromic acid.

The Nature of Atmosphere Contaminants in a Chromate Factory

A preliminary survey of the factories and their processes indicated that the atmosphere contaminants were likely to be particulate. Only in certain 
processes, such as feeding chromate liquors into tanks, or flooding frit in the extraction tanks, were chromium compounds likely to be encountered in droplet or spray form. All the principal reactants contributed to the factory atmosphere. These contaminants varied in proportion and included the following: (a) chromite ore; (b) sodium carbonate ; (c) calcium carbonate (as dolomite or limestone) all of which were in the crude form and well mixed before feeding into the roasting furnace ; $(d)$ products of the various interactions of $(a)$ and $(b)$ as indicated by equations 1-3 ; (e) monochromates, either sodium or potassium ; (f) dichromates, either sodium or potassium; (g) miscellaneous dusts with compositions depending on the other processes in the factory, for example, chromic acid and chrome tan.

Chromite appeared to be the principal insoluble substance, although calcium carbonate and some of the products of the roasting process such as $\mathrm{Fe}_{2} \mathrm{O}_{3}$, $\mathrm{FeO}$, magnesia, and silica contributed to this fraction. The amount of free silica was unlikely to be high, as most samples of chromite are said to contain less than $6 \%$ and many less than $2 \%$ (Thorpe and Whiteley, 1946b). The other products of the reactions were soluble.

Interconversion of Monochromate and Dichromate

The wide range of atmosphere contaminants listed in the previous section indicated that it might be necessary to attempt a quantitative separation of the soluble salts of chromium. A further argument in favour of taking this step was the suggestion that the monochromate ion might cause lung cancer (Machle and Gregorious, 1948). However, consideration of the factors influencing the interconversion of mono- and dichromates led to the conclusion that such a separation, particularly of factory atmosphere contaminants, would be impracticable if not impossible.

The interconversion of mono- and dichromates is illustrated by the simplified equilibrium equation (6) where $B$ is a base e.g., sodium or potassium.

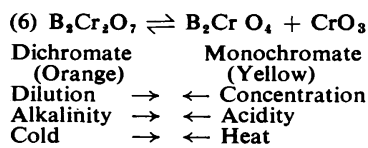

Two of the chief factors influencing this equilibrium are $p \mathrm{H}$ and dilution. Thus a shift in $p \mathrm{H}$ towards the acid side will favour the formation of dichromate ions ; this is used in the manufacture of bichromate. On the other hand alkalinity will favour the monochromate. Dilution of a solution of a dichromate increases the amount of monochromate. Concentration of a solution of a monochromate shifts the equilibrium in favour of the dichromate.
According to Dehn (1914) concentrated solutions contain, in addition to mono- and dichromate, triand even tetrachromate ions, whereas in very dilute solutions possibly of the order of $0.003 \%$ or less, only chromate ions are present. Other authors have expressed similar views, for example Mellor (1930).

Bourne and Yee (1950) have demonstrated that rafter and air-borne dust samples are predominantly alkaline. Although no $p \mathrm{H}$ measurements were made on samples from British factories, many of them were heavily contaminated with sodium carbonate and must have been alkaline.

Furthermore, many of the samples from the British factories were taken in steam filled atmospheres, e.g., near wash tanks during flooding, and by centrifugal dryers, thus adding to the moisture content of the air-borne particles and therefore increasing the dilution.

It was concluded from these observations that moist air-borne particles would contain variable mixtures of mono- and dichromates, but that the tendency would be for the equilibrium to be balanced in favour of the monochromate ion.

Although Martin, Hixson, and McNabb (1948) have described a good method for estimating monoand dichromate ions in each other's presence in concentrated solutions by a spectrophotometric technique, it was felt that this method would not be applicable to the survey, particularly as no method could be found of preserving the monochromatedichromate equilibrium for trapped particles or droplets.

These considerations led to the decision to estimate only mass concentrations of total insoluble and total soluble chromium compounds.

Although the same general principles of the manufacturing process applied in each of the three factories, the lay-out of the works varied slightly, and there were differences in the types of equipment used. The concentration of contaminants in the atmosphere varied because the factories were roofed and not completely walled. This allowed changes in the weather, speed and direction of the wind, and relative humidity, to affect conditions in the working atmosphere and made accurate comparisons of the environmental conditions in the three factories impossible.

\section{Experimental Methods}

Sampling.-Atmosphere samples were taken at points near each stage in the process, and having regard to the differences in the lay-out of the works, at comparable points in each factory. The positions of these sampling points are given in Table 1. Except where an obvious change in the concentration of atmosphere contaminants occurred, as in the vicinity of the drying cubicles, single (grab) estimations were made at all points. Air samples 
from 1 to $10 \mathrm{cu} . \mathrm{m}$. in volume were collected over periods of time varying from half to five hours.

Two general methods were employed in trapping atmosphere contaminants. They were collected in dilute aqueous alkali after passage through the jet of an impinger acting as a critical orifice or on dry Pyrene filters.

Treatment of Samples and Analytical Methods.-By means of the two methods described in the previous paragraph samples, either soluble or insoluble in alkali, were collected. In order to convert it into a soluble form, the insoluble material was separated from the liquid in the impinger flask by centrifuging, and fused with excess sodium carbonate at $800^{\circ} \mathrm{C}$ for two hours. Pyrene filters were washed with dilute alkali to remove the soluble compounds and the residue, containing chromite and other insoluble matter, was treated in the same way as the insoluble material in the impinger flask. Estimations of chromate were carried out using the standard diphenyl carbazide method (Jacobs, 1941). Bourne and Yee (1950) used filter paper for the collection of their samples and then analysed them for trapped chromium by a polarographic technique devised by Urone, Druschel, and Anders (1950a). This method is stated to have a sensitivity of the order of $0.02 \mu \mathrm{g} . / \mathrm{ml}$. Scott (1939) states that at least $0.0001 \mathrm{mg}$. of chromium may be detected by the use of diphenyl carbazide, and more recently Urone, Druschel, and Anders (1950b) have employed this reagent to estimate $0.005 \mu \mathrm{g}$. of chromium in atmosphere samples and mists. It is considered that the polarographic and colorimetric methods are sufficiently specific and accurate to permit reasonable comparisons to be made between the two studies.

\section{Results}

Detailed results are set out in Table 1. For the purpose of presentation the process is divided into phases, and it will be seen that there is wide variation in the concentrations of the soluble and insoluble compounds of chromium. The principal features are that during mixing of the reactants, phase 1 , the

TABLE 1

COMPARISON OF AVERAGE CONCENTRATIONS OF CHROMIUM IN BRITISH AND AMERICAN CHROMATE FACTORIES

\begin{tabular}{|c|c|c|c|c|c|c|c|c|c|c|c|c|}
\hline \multirow{2}{*}{$\begin{array}{l}\text { Phase } \\
\text { in } \\
\text { Process } \\
\text { No. }\end{array}$} & \multirow{2}{*}{ General Description } & \multirow{2}{*}{$\begin{array}{c}\text { Details of } \\
\text { Sampling Points }\end{array}$} & \multicolumn{4}{|c|}{$\begin{array}{l}\text { British (Concentrations } \\
\text { in mg. Cr./cu.m.) }\end{array}$} & \multirow{2}{*}{ Total } & \multirow{2}{*}{$\mathrm{Cr}^{+3}: \mathrm{Cr}^{+6}$} & \multicolumn{4}{|c|}{$\begin{array}{l}\text { American (Concentration; } \\
\text { in mg. Cr./cu.m.) }\end{array}$} \\
\hline & & & $\sqrt{\mathrm{Cr}+3}$ & Range & $\begin{array}{c}\mathrm{Cr+6} \\
\text { Average }\end{array}$ & Range & & & $\mathrm{Cr}+3$ & $\mathrm{Cr}+6$ & Total & $\mathrm{Cr}+\mathrm{s}: \mathrm{Cr}+$ \\
\hline 1 & $\begin{array}{l}\text { Pre-reaction phase: } \\
\text { mainly insoluble chro- } \\
\text { mium (chromite) (lime } \\
\text { and ash) }\end{array}$ & Near mixers only & $2 \cdot 14(3)$ & $\begin{array}{l}3.27- \\
0.818\end{array}$ & $0.005(3)$ & $\begin{array}{c}0.01- \\
0.002\end{array}$ & $2 \cdot 145$ & $430: 1$ & $\begin{array}{l}1.52 \\
1.2\end{array}$ & $\begin{array}{l}0.03 \\
0.1\end{array}$ & $\begin{array}{l}1.55 \\
1.3\end{array}$ & $6: 1 \quad(6)$ \\
\hline 2 & $\begin{array}{l}\text { Reaction phase: con- } \\
\text { version of insoluble } \\
\text { chromite to soluble } \\
\text { chromate (roast) }\end{array}$ & $\begin{array}{l}\text { Discharge end of } \\
\text { furnace; by frit } \\
\text { hopper during dis- } \\
\text { charge; by wash } \\
\text { tanks during emp- } \\
\text { tying of frit }\end{array}$ & $0 \cdot 17(9)$ & $\begin{array}{c}0.660- \\
0.0033\end{array}$ & $0.029(10)$ & $\begin{array}{r}0.146- \\
0.0005\end{array}$ & $0 \cdot 199$ & $5 \cdot 8: 1$ & 0.26 & 0.39 & 0.65 & $2: 1(62)$ \\
\hline 3 & $\begin{array}{l}\text { Reaction } \\
\text { tinued : } \\
\text { (filtering) }\end{array}$ & $\begin{array}{l}\text { By wash tanks } \\
\text { before, during and } \\
\text { after flooding; dig- } \\
\text { ging out of ex- } \\
\text { tracted frit ; run- } \\
\text { ning off mono- } \\
\text { chromate liquor }\end{array}$ & $\overline{0.037(6)}$ & $\begin{array}{c}0.214- \\
0.0009\end{array}$ & $0 \cdot 52(10)$ & $\begin{array}{r}4 \cdot 15- \\
0 \cdot 0005\end{array}$ & 0.557 & $1: 14$ & 0.08 & $0 \cdot 12$ & 0.2 & $2: 1(10)$ \\
\hline 4 & $\begin{array}{l}\text { Formation of dichrom- } \\
\text { ate (liquor) }\end{array}$ & By acidifier tanks & $0.014(7)$ & $\begin{array}{c}0.094- \\
0.0002\end{array}$ & $0.056(8)$ & $0.175-5$ & 0.070 & $1: 4$ & 0.09 & 0.09 & $0 \cdot 18$ & $2: 1(12)$ \\
\hline 5 & $\begin{array}{l}\text { Concentration phase } \\
\text { and drying of soluble } \\
\text { chromates (shipping) }\end{array}$ & $\begin{array}{l}\text { By centrifugal dry- } \\
\text { ers inside and out- } \\
\text { side cubicles; by } \\
\text { evaporating pans }\end{array}$ & $0.0053(7)$ & $0.019-$ & $0.88(11)$ & $\begin{array}{l}5.68- \\
0.0004\end{array}$ & 0.8853 & $1: 166$ & $0 \cdot 3$ & $0 \cdot 2$ & 0.5 & $8: 1 \quad(3)$ \\
\hline 6 & $\begin{array}{l}\text { Packing of dry purified } \\
\text { soluble chromate (ship- } \\
\text { ping) }\end{array}$ & $\begin{array}{l}\text { By mechanical chro- } \\
\text { mate filler; by } \\
\text { men filling drums } \\
\text { manually }\end{array}$ & $0.0009(3)$ & $0.0022-$ & $0.467(5)$ & $\begin{array}{c}0.92- \\
0.051\end{array}$ & 0.4679 & 1:519 & - & - & - & - \\
\hline 7 & $\begin{array}{l}\text { Miscellaneous processes } \\
\text { in addition to main } \\
\text { ones ; for example: } \\
\text { (1) Chromic acid } \\
\text { (2) Milling chrome } \\
\text { (3) Mixhate dichrome } \\
\text { and sulphur } \\
\text { (4) Milling chrome } \\
\text { (5) Chide } \\
\text { (6) Waste hopper }\end{array}$ & & $\begin{array}{cc}0.036 & (3) \\
0.5 & (1) \\
- & \\
0006 & (1) \\
0.170 & (1)\end{array}$ & $\begin{array}{c}0 \cdot 106- \\
0 \cdot 0015 \\
0.5 \\
- \\
0.0006- \\
0.005 \\
0.170\end{array}$ & $\begin{array}{l}0.087(3) \\
0.003(1) \\
17.0(1)(?) \\
0.005(1) \\
0.003(1) \\
0.002(1)\end{array}$ & $\left|\begin{array}{l}0 \cdot 142- \\
0.034 \\
0.003 \\
17.0(?) \\
0.005 \\
0.003 \\
0.002\end{array}\right|$ & $\begin{array}{l}0.123 \\
0.503 \\
17.0 \\
0.0056 \\
0.003 \\
0 \cdot 172\end{array}$ & $\begin{array}{c}1: 2 \cdot 1 \\
166: 1 \\
- \\
1: 8 \\
\overline{85: 1}\end{array}$ & $\begin{array}{l}- \\
- \\
- \\
- \\
=\end{array}$ & $\begin{array}{l}- \\
- \\
- \\
- \\
=\end{array}$ & $\begin{array}{l}- \\
- \\
- \\
- \\
-\end{array}$ & $\begin{array}{l}- \\
- \\
- \\
- \\
-\end{array}$ \\
\hline
\end{tabular}

A dash (-) indicates that no values are available. Figures in brackets indicate the number of samples. The equivalent name of the American process (Bourne and Yee, 1950) is placed in brackets after the descriptions of the phases. Approximate American figures are calculated from diagram 1 in the paper by Bourne and Yee (1950). 
insoluble form $\mathrm{Cr}^{+3}$ is far in excess of the soluble, $\mathrm{Cr}^{+6}$, whereas in the drying and packing, phases 5 and 6 , the reverse applies. The average concentrations of chromium in the atmospheres of British and American factories are based on 96 representative samples from the factories of Great Britain, and 121 from those in the United States of America.

\section{Discussion}

The wide range of many of the British values, e.g., in reaction phase 2 , suggests the influence of variable ventilation since the processes were similar and continuous, and sampling points placed at comparable points in the three factories. The scatter is not so marked in the American figures. This could be due to greater control of ventilation near each plant in the process, but no definite information is available on this point.

It is obvious that there is some danger in making absolute comparisons between British and American figures, particularly as the samples were grabs in both cases. At best it can be said that the British figures, and probably the American, represent values likely to be encountered during average working periods.

Elkins (1950) states that the maximum allowable concentration of $\mathrm{Cr}$ as $\mathrm{CrO}_{3}$ is $0.1 \mathrm{mg}$./cu.m. This is equivalent to $0.048 \mathrm{mg}$. $\mathrm{Cr} /$ cu.m. Many of the values recorded in the British and American figures are much higher than this, and although perforation of the nasal septum appeared to be common among many of the British workers, there was no unduly high incidence of lung cancer (Bidstrup, page 302).

Industrial hazards due to chromium are usually attributed to water soluble derivatives of hexavalent $\left(\mathrm{Cr}^{+6}\right)$ chromic acid. There are chromic acid itself and the mono- and dichromates. It is commonly stated that solubility in water is an important property in determining the toxicity of these compounds (Elkins, 1950). For example, lead and zinc chromate are stated to be less toxic than the corresponding sodium and potassium salts. However, in view of the lack of any information to the contrary, it is felt that the insoluble trivalent $\left(\mathrm{Cr}^{+3}\right)$ forms such as chromite cannot be arbitrarily defined as "safe" compounds. Therefore it seems reasonable to suggest that the most dangerous points in the manufacture of chromate will be those which produce the highest levels of insoluble and soluble chromium compounds. In the factories studied, these points were to be found at the pre-reaction phase where the insoluble chromium reached a maximum value of $3.27 \mathrm{mg}$./cu.m. and the drying phase where the soluble form reached the level of $5.6 \mathrm{mg}$./cu.m.
Men working at these points wore adequate dust masks and were not continuously exposed to the highest concentrations. The mixers were situated in fairly open areas of the factory and were well ventilated. The centrifugal dryers were housed in small cubicles more or less protected from draught. They were also isolated from the general atmosphere of the factory.

During the process of drying, which lasted from two to three hours, the workman was not present in the drying cubicle for more than a few minutes. His main functions were charging the dryer, keeping watch to see that it was working properly, and finally emptying it before the packing of the finished product. In the early stages of drying the hazard was relatively low if measured by atmosphere levels of chromium, but these increased rapidly to the higher values after two to three hours.

\section{Summary}

A survey has been made of the contamination of the atmosphere by soluble and insoluble chromium compounds in the three factories in Great Britain making basic chromates from the ore, chromite. The results are compared with those obtained in a similar survey in the United States of America.

The maximum concentrations of both soluble and insoluble forms of chromium in the atmospheres of factories in Great Britain are greater than those found in the factory in the United States of America, and the minimum concentrations are lower. The main point of similarity is the very high ratio of $\mathrm{Cr}^{+3}$ to $\mathrm{Cr}^{+6}$ in the ore mixing stage.

The authors wish to express their thanks to the management in each of the chromate producing factories for their cooperation and hospitality. They also wish to thank Dr. Donald Hunter for his help and encouragement, Dr. P. Lesley Bidstrup for many helpful discussions, and Messrs. E. King, P. N. Casbolt, A. J. Hobbs, and Mrs. S. Cox for technical assistance.

\section{REFERENCES}

Bourne, H. G., and Yee, H. T. (1950). Industr. Med. and Surg. $19,563$.

Dehn, W. M. (1914). J. Amer. Chem. Soc., 36, 829

Elkins, H. B. (1950). The Chemistry of Industrial Toxicology,

p. 69. New York.
Jacobs, M. B. (1941). Analytical Chemistry of Industrial Poisons, Hazards, Solvents, p. 207. New York.

Machle W., and Gregorius, F. (1948). Publ. Hlth Rep., Wash., 63, i114.

Martin, E. W., Hixson, A. N., and McNabb, W. M. (1948). Anal. Chem. 20, 1043

Mellor, J. W. (1930). Modern Inorganic Chemistry, p. 565. London. Partington, J. R. (1946). General and Inorganic Chemistry, p. 748 London.

Scott, W. W. (1939). Standard Methods of Chemical Analysis, Vol. I, p. 291. New York

Thorpe, F. J., and Whiteley, M. A. (1946a). Dictionary of Applied Chemistry London, Vol. 3, p. 110.

Urone, P. F., Druschel, M. L., and Anders, W. H. (1950a). Anal.

- , Chem., 22, 1317. 